\title{
The Management Innovations of Business Based on Lean Management Analysis Jia Dian ${ }^{1, a}$
}

\author{
${ }^{1}$ Qinghai Nationalities University, Xining , Qinghai , P.R.C. 810007 \\ a jiatianabc@163.com
}

Keywords: Lean production thinking; Management; Enterprise management

\begin{abstract}
With the continuous development of economic globalization, the management mode of enterprises has undergone a major change in the process of expansion. In this process, the major problem of business management is how to use scientific means to manage the enterprise in the rapidly changing market environment, reduce the production cost of the enterprise, and maximize the profit of the enterprise. Therefore, the lean enterprise management mode came into being, and gradually become an important management mode value by enterprise managers. Lean management is the advanced form of modern enterprise management. Through reasonably allocating relevant resources of enterprises and advantages, it can effectively enhance the economic benefits and promote the continuous development of enterprises. The managers of enterprises should pay enough attention to the lean management mode. By fully understanding the lean management mode of the enterprise, it can be applied in the management of the enterprise so as to enhance the economic benefits and promote the continuous development of the enterprise.
\end{abstract}

Lean management is a way to integrate enterprise resources through scientific and reasonable management means to maximize the utilization of resources, reduce production costs and enhance the efficiency of enterprises. The concept of lean management was initially implemented in the management of manufacturing enterprises. With the continuous development of social economy, lean management has been continuously applied to other enterprises, and has played a remarkable effect. It evolved from the initial management of a business and commodities into an core management strategy of the whole enterprise, which can improve customer service satisfaction, reduce operating costs and improve the service of enterprises, and continuously increase the economic benefits of enterprise from many aspects. Through the use of a lean management model, SMEs can enhance their management level so as to gain a foothold in the market competition and seek development. For large enterprises, lean management can also expand the advancement of enterprises to improve and ease the impasse for the development of large-scale enterprises, which is of great significance to the development of enterprises.

\section{The Basic Connotation of Lean Management}

The thought of lean management thinking appeared at 1950s. The Toyota Motor Corporation in Japan was caught in a serious survival crisis due to the heavy market competition pressure. In order to gain a firm foothold in the fierce competition in the automobile industry and further develop, Toyota Motor Corporation has established a scientific and rigorous organizational production management system with the minimum investment cost for maximum economic benefits. Eventually, Toyota Motor Corporation has effectively raised its own economic benefits through this system of production management and gained a foothold in the automotive industry, gradually becoming one of the most famous automobile manufacturers today. After that, scholars from all over the world summed up the theory of lean production in the research of the organization and production management system of Toyota Motor Corporation, which was valued by many enterprises and became the complete lean management system after continuous improvement.

Lean management is a scientific management system that integrates business philosophy, management method, technology and management. Its core lies in the word "lean", which means to invest as little as possible. For the manufacturing enterprises, the costs incurred by the 
manufacturing enterprises in the production process can be reduced by increasing the utilization rate of resources, reducing the production costs and improving the production cycle. For service-oriented enterprises, it can also be achieved by enhancing the internal efficiency of enterprises, quickly meeting the needs of customer, reducing the waiting time of customers in the service process. It also means that the sale effects can be achieved through marketing, production and other strategies and then enhance their economic returns, so that enterprises can take more market share. Therefore the strength of enterprises can be enhanced and enterprises continuity develop.

\section{The Features of Lean Management}

With the continuous development of market economy, the competition between various industries is increasingly fierce. The most important way to stand out in the market competition is to enhance your own competitiveness, which also requires the lean management in the enterprise management. The concept of lean management model is mainly reflected in the following aspects.

First, to reduce costs. Reducing costs is the core idea of lean management. Reducing costs does not mean cut corners, but to maximize the use of each part of the resources. The ideal state is zero inventory of enterprises without waste, and the enterprises react to customers' requirements as quickly as possible, during which the enterprises should continuously keep improving the products and services, so as to gradually develop and integrate the lean management into the production and service process of the enterprise and comprehensively enhance the competitiveness of the enterprise.

Second, people-oriented. In the process of enterprise management, people are the dominant. any activities of enterprises are inseparable from human control, therefore, there must be a process of pursuing the democratization and scientific decision-making in the lean management. By emphasizing the mutual cooperation among the employees in the enterprise, the employees can have a stronger sense of belonging to the enterprise, which can form a good working atmosphere of mutual respect and cooperation, and mobilize the enthusiasm of the employees.

Third, process management. The pursuit of lean management is a continuous process of change and innovation. A core objective must be established first. In the process of pursuing the goal, there may be some problems in the management of the enterprise. At this moment, the enterprises will need to make corresponding improvements to these problems so as to achieve the initial goal. Since this goal is constantly changing, the pursuit of a lean management model has become an endless loop.

Fourth, quality management. Lean management saves costs as well as paying attention to the quality of products and services. In lean management, the quality of the product should not be tested out, but should be paid great attention in the production process, In lean management, each employee's quality awareness should be fully nurtured, so that the quality of products and service can be put in the first place by employees in the process of production and service. If there is any quality problem appearing in the production process, the staff should stop the production promptly and solve the problems so as to ensure the quality of products and services and enhance the competitiveness of the enterprises.

\section{The Necessity of Lean Management}

Now many enterprises in our country use extensive management and can not grasp the details, resulting that in the production and service the enterprise will usually invest a lot, which will lead to a lot of money wasted, causing high costs, accumulation of goods, financial losses and other phenomena that are bad for both the economic benefits and the development of enterprises. Therefore, the traditional management mode should be changed to lean management mode, so as to improve the economic benefits of the enterprise and promote the continuous development of the enterprise. The advantages of lean management mainly reflected in the following aspects. 


\section{Saving Business Resources and Increase Business Efficiency}

Enterprises are the main driving force for promoting the economic development of our country. They consume a large amount of resources in the process of operation. It will be difficult for enterprises to make full use of resources without a good business management model. The waste of abundant resources and funds increased the cost of production and services, decreasing the economic benefits of enterprises and constraining the development of enterprises. The lean management can effectively improve the utilization rate of enterprise resources, reduce production costs and improve the economic efficiency of enterprises. The standards for the current degree of resource consumption can be set through clarifying the ratio of the inputs and outputs of enterprises, based on which an improved measure can be set to reduce the production costs of enterprises and enhance the enterprises' efficiency. Second, we should implement the concept of leanization in the enterprise and establish a perfect lean management system so as to save the company's investment funds, increase the amount of capital circulation, speed up the turnover of capital, reduce the risk of business operations, and expand the investment direction of enterprises. Finally, it is necessary to correctly evaluate the products or services provided by the enterprises themselves, abandon the meaningless parts of them, reduce the waste, and better meet the needs of customers, realizing the on-demand production and promoting customers' experience.

\section{Ensuring the Survival and Development of Enterprises}

Most of the earnings of enterprises are directly related to the management mode of managers. Therefore, for the better development of enterprises, the traditional extensive management methods should be replaced by the lean management. On the one hand, the managers should be careful in the products and services, and upgrade and change products and services according to the basic requirements of the market, so as to better meet the market demand. On the other hand, the managers should be close to the market, having a clear grasp of the basic conditions of each commodity, raw material and service in the market and understanding the needs of our customers in order to conduct targeted sales and production. Finally, the lean management is needed. By controlling the cost of production and service, we establish a perfect lean management system so that employees can penetrate the lean concept into their daily work to form a closed-loop operation, which makes the work of employees and the management of enterprises more manageable, making an important contribution to reducing the production cost and improving the efficiency of the enterprise.

\section{It is Conducive to Shaping Corporate Culture}

Lean management, on the one hand is a modern enterprise management mode. On the other hand, it also has a profound impact on the daily work of employees. Therefore, lean management can be developed as a corporate culture. The core idea of lean management is to simplify the workflow of the staffs to the greatest extent, which helps to reduce waste in the process of work and prevent meaningless behaviors, so as to provide better goods or services to meet the needs of customer. This mode emphasizes the role of the individual, so that each employee in the work can maximize the people's subjective initiative. The employees not only complete the orders of superiors, but also integrate into work and participate in decision making of enterprises and work. Also, lean management focuses more on teamwork. In the process of lean management, each department's work is not done independently, but through cooperation with each other, which greatly improved the work efficiency of departments. Therefore, the lean management is embodied in the corporate culture, which can effectively enhance team spirit of staffs, so that employees can better cooperate with each other and the overall efficiency of the enterprise enhanced.

\section{Meeting the Needs of Market Development}

With the continuous development of market economy and the continuous formation of global value chain, many enterprises are constantly expanding and the market competition is fiercer and fiercer. As a result, new requirements are put forward on the operational efficiency of enterprises. In this context, the enterprises must reduce their own costs to obtain greater benefits and promote the overall economic growth, which also led to that the traditional extensive mode of enterprise management can not meet the needs of market development or promote the development of 
enterprises. With the development of market economy, the scale of enterprises becomes larger and larger, which brings about a broader development prospect as well as causes enterprises to consume more resources. The traditional mode of resource use is too wasteful, which leads to the need for a new business management model, while the lean performance management model is in line with the needs of business development. The lean performance management can not only reduce the total amount of resources consumed in production and service, but also effectively increases the economic benefits of the enterprise, enhancing the working abilities of the staffs and promoting the continuous improvement and development of business.

\section{Helping to Promote the Reform of Enterprise Management Mode}

Due to the continuous expansion of enterprises in the development process, the detailed work of each department is increasing, and even the details of each employee's work vary. The management model and corresponding system established in the beginning of the can only meet the current business operations and management. After the continuous expansion of the enterprise scale, the traditional enterprise management model can not meet the needs of the development of enterprises. The disadvantages of the traditional management model have become more obvious. Therefore, the traditional management mode should be changed accordingly. The use of the lean management model can effectively push the reform of the enterprise management mode, change the traditional business management mode and establish a new management mode more in line with the actual development of the enterprise, so as to lay a solid foundation for the development of the enterprises.

\section{The Implementation of Lean Management}

\section{Paying Attention to Personnel Training}

In the process of lean management, it is necessary for the enterprises to change the traditional commodity-centric management mode and enhance the emphasis on people, forming a management concept of people-centered management, so as to achieve the core idea of lean management. Therefore the enterprises must show high respects to personnel, building team with people of the abilities in management, technology and skills, which also requires enterprises to conduct job training of personnel to enhance their work ability and integrate the idea of lean management into all aspects of work, roundly improving the lean management of enterprises.

\section{Meeting the Basic Needs of Customers to Enhance the Market Competitiveness}

The market is the starting point for production services activities. In the process of production and service, the enterprises must pay enough attention to customers and look into the needs of them. Also, the enterprises should enrich the diversity of their products or services to enhance the service levels to meet the requirements of customers. Therefore, in the process of lean lean management, the enterprises need pay more attention to the customers, making the customers not only a part of the market, but also a part of lean management. At the same time, the enterprises should also use market research to know the basic needs of customers and carry out the appropriate design and improvement to promote business goods and services to meet requirements of customers, enhancing the competitiveness of enterprises.

\section{Creating a Lean Corporate Culture}

Lean management is not only the management of enterprises, but also a corporate culture. The construction of enterprise culture can effectively standardize the behavior of employees and managers, establish correct values, enhance the cohesion, enthusiasm and work efficiency of staffs. The corporate culture of lean management bring an important impetus to enterprises through developing resource conservation of employees, emphasis on product and service quality, making employees participate in decision-making, enhance employee cohesion and other outstanding concepts. Therefore, in the process of enterprise lean management, it is necessary to infiltrate the core idea of lean management through lectures, seminars and other forms, so that employees understand it and bring this concept into daily work, which can enhance the work effectiveness of employees. At the same time, the establishment of corporate culture contribute to the improvement of corporate image because of the improvement of the quality of goods or services. Corporate image is an intangible asset. On the one hand, corporate image can help enterprises have a certain fixed 
customer, therefore makes the enterprise occupy a certain market share in the market. On the other hand, the improvement of the corporate image can bring more customers, which help to raise the potential profits of the enterprises, so that the enterprises have a broader prospect of development.

\section{Pursuit of Effective Production and Service}

There is a difference between effectiveness of the production and service of enterprise. Only the effective production and service have value, and can promote the economic growth of enterprises. However, ineffective production and service can just bring certain economic burden to the enterprise and reduce the image of the enterprise, making the enterprise suffer losses. There are a large number of ineffective production in the process of enterprise production and service. For example, the excessive use of employees, excessive production quantities, accumulation of resources, and complicated departmental work efficiency will all lead to great production costs. Therefore, the enterprises need to make corresponding changes to ineffective production and service so that the production and services can be more concentrated on the effective level, and the economic benefits of the enterprises being enhanced.

\section{Build a Networked Production System}

With the continuous development of information technology, the Internet has been widely used in all the fields. As the Internet has its advantages in the development of enterprises, making better use of the Internet has also become an important factor in the development of enterprises. In the use of lean management, the Internet can be integrated with lean management organically according to the actual needs of enterprises, so as to enhance the enterprises' capabilities of lean management.

With the constant development of market economy, the constant formation of global value chain and the increasingly fierce market competition bring about great development prospects as well as huge risks to the enterprises, which bring new requirements to the enterprise management mode. In this context, the enterprises must increase their production and service quality and obtain greater economic benefits by reducing the costs so as to promote the overall economic growth. Lean management model, which focuses on the use of the smallest cost for maximum benefit, has an important significance in the modern enterprises. Therefore, it is necessary to attach importance to the lean management model. The applying of lean management and its concept to enterprises can promote the economic growth of enterprises on the one hand, and on the other hand provide an important impetus to the construction of corporate culture and ideology so that enterprises can gain a firm foothold in the fierce market competition and obtain a broader development prospects.

\section{References}

[1] W. Z. Liu. On the Construction of Internal Control System of the Group Company[J].MANAGEMENT \& TECHNOLOGY OF SME(Volume One), 2009, 10(14): $15-16$.

[2] X. J. Cheng. Analysis on Application Strategies of Lean Management in Chinese Enterprise[J]. Qilu Petrochemical Technology, 2011, 39(2): 146-147.

[3] X. F. Zhao. Reflections on Enterprise Implementing Lean Management in New Period[J].Science \& Technology Information, 2011, 10(19): 135-137. 